\title{
Analytical Methods in the Quality Control of Scientific Publications Part V: The Fraud of Pseudoscientists Based on False Measurements and Method Development
}

\author{
Ilia Brondz \\ Norwegian Drug Control and Drug Discovery Institute (NDCDDI) AS, Ski, Norway \\ Email: ilia.brondz@gmail.com
}

Received 19 June 2015; accepted 25 July 2015; published 28 July 2015

Copyright (C) 2015 by author and Scientific Research Publishing Inc.

This work is licensed under the Creative Commons Attribution International License (CC BY). http://creativecommons.org/licenses/by/4.0/

(c) (i) Open Access

\begin{abstract}
Despite the obvious frauds published in [1] [2] and the involvement of Editors and Editors in Chief of the journals in the publication of these fraudulent papers, the Editors in Chief of publishers have not taken any action to retract the fraudulent papers or to dismiss the corrupt editors. By this passivity, these Editors in Chief are supporting plagiarism, dissemination of fraudulent data, lies and making published information unreliable. In the present paper, we evaluate examples of bold, fraudulent publications and give the names of some Editors directly participating in concealing fraudulent publications, together with the names of Editors in Chief who also concealed and covered the facts of fraud and were reluctant to remove the fraudulent papers from circulation or to remove cheaters from editorial positions. The truth is universal and international; in contrast, the lie is individual and partisan, social, political, confessional, cultural and dirty. Knowledge is a truth that is part of the Universe. Lies are a tool of manipulation and can exist only in distinct environments that produce and support them. In this paper, we will show how artificial prefabricated analytical procedures were used to disseminate false data with the aim of substituting the truth with fraud.
\end{abstract}

\section{Keywords}

Plagiarism, Dissemination of False Data, False Method Development, Corrupt Editors, Artificial Analytical Procedures, Primaquine, Quinocide, Antimalarial Drugs

\section{Introduction}

More than a decade ago, the antimalarial drug primaquine was reported to be heavily contaminated with the

How to cite this paper: Brondz, I. (2015) Analytical Methods in the Quality Control of Scientific Publications Part V: The Fraud of Pseudoscientists Based on False Measurements and Method Development. International Journal of Analytical Mass Spectrometry and Chromatography, 3, 25-31. http://dx.doi.org/10.4236/ijamsc.2015.32003 
isomer quinocide, which is much more toxic than primaquine [3]. Today, quinocide is not in use, even in its country of origin, because of its toxicity. Both primaquine and quinocide are antimalarial agents, and are isomers. In tablets, there are four different substances: two stereoisomers of primaquine and two stereoisomers of quinocide. These substances have different toxic, pathological and pharmacological effects on animals and humans [4]-[6]. In 2004, qualitative and quantitative information about primaquine tablets as mixtures of four individual substances and the influence of the contaminant quinocide on the overall toxicological effects of the drugs in these tablets was published [7]. More than 500 million people take these tablets as curative medicine every year. It is a very profitable business for the pharmaceutical industry to produce this medicine from cheap, contaminated raw ware primaquine. Revelation of the contamination of this drug with more toxic substances was and is being ignored by the pharmaceutical industry. Initially, authorities and the pharmaceutical industry suppressed all information about contamination of this drug [8]. This allowed the pharmaceutical industry to sell stockpiles of tablets highly contaminated by quinocide. The contamination level allowed by pharmacopoeias was 6\% [9] [10], but in reality it was significantly higher [11]. Despite all attempts of pharmaceutical authorities to ignore the presence in primaquine of alien toxic substances and all efforts to prevent dissemination of knowledge about this, the latest published pharmacopoeias were compelled to acknowledge the force of facts and require a reduction of the presence of quinocide under the definition of "related substances" to 3\% [12]-[16]. All these pharmacopoeias avoided naming the alien toxic contaminant as quinocide directly; instead, the contaminant was named as "related substances". After the old tablet stockpiles were consumed, the level of allowed contamination with "related substances" was reduced in pharmacopoeias to $1.5 \%$.

Several methods for determination of the toxic contaminant quinocide in raw ware primaquine and tablets have been published: [17] [18] by using GC-MS in 2004-2005, [19]-[21] by using HPLC and HPLC-MS in 2005, [22]-[24] by using SFC-MS in 2007-2009, and by using gas chromatography-mass spectrometry with supersonic molecular beams (SMB) in 2009 [25]. The biological consequences of primaquine contamination with quinocide were presented in 2011 [26]. All this information was presented over a significant period of time at international meetings, and in technical and scientific international journals and could not be missed by any serious scientist. In Biomedical Chromatography, Elbashir et al. published a paper [27] "Determination of Quinocide as Impurity in Primaquine Tablets by Capillary Zone Electrophoresis"; they also mentioned some of the previous publications that described quinocide analyses in primaquine. All this pointed to the good knowledge about the presence of quinocide in primaquine by Elbashir et al. Primaquine and quinocide are isomers. They have similar molecular formulas and similar UV spectra [8] and undergo the same chemical reactions and by derivatization give isomeric products with similar UV spectra.

\section{Unstoppable Fraud}

As mentioned above, primaquine and quinocide are isomers and have similar natures and similar reactions under derivatization and their derivatives have similar UV spectra. The presence of quinocide in primaquine was well known to Elbashir et al. [27]. Despite this, Elbashir et al. [28] published "Spectrophotometric Method for Determination of Primaquine in Pharmaceutical Formulations via Derivatization with 1, 2-Naphthoquinone-4Sulfonate" by Aida Makram Nouralla Altigani, Abdalla Ahmed Elbashir in Austin Journal of Analytical and Pharmaceutical Chemistry. Nothing was mentioned in this paper about interfering factors or interfering substances, or about the interference of quinocide in the analytical procedures. This paper does not mention the presence of quinocide in primaquine and its reaction with 1, 2-naphthoquinone-4-sulfonate, or that the UV spectrum of the product of derivatization is an interfering factor. This publication is a shameful fraud, but it is not the first fraud published by Elbashir et al. His series of shameful fraudulent publications were criticized in [29]. In connection with publication [27], the corrupt nature of acceptance for publication of this paper was discussed in [29]. The Editor in Chief of Current Chromatography, Pavel N. Nesterenko, was contacted (Figure 1) to give his evaluation of the disclosure presented in [29]. The Associate Editor of Current Chromatography, H. Y. Aboul-Enein (National Research Centre, Cairo, Egypt) was the corresponding author of fraudulent publication. An explanation of his role in the corrupt acceptance for publication of paper was requested.

The following answer was received (Figure 2).

Response to Mr. Nesterenko is shown in Figure 3.

After one month there was no answer from Mr. Nesterenko, the same situation is current despite my subsequent letter to Mr. Nesterenko (Figure 4). 


\begin{tabular}{|c|} 
Current Chromatography \\
http://benthamscience.com/journal/editorial-board.php?journalID=cchg\#top \\
Editor-in-Chief: Pavel N. Nesterenko \\
Australian Centre for Research on Separation Science (ACROSS) School of Chemistry, University of Tasmania \\
Private Bag 75, Hobart, TAS 7001, Australia \\
Associate Editor(s): H.Y. Aboul-Enein \\
National Research Centre, Cairo, Egypt
\end{tabular}

Figure 1. Some leading members of the editorial board of Current Chromatography.

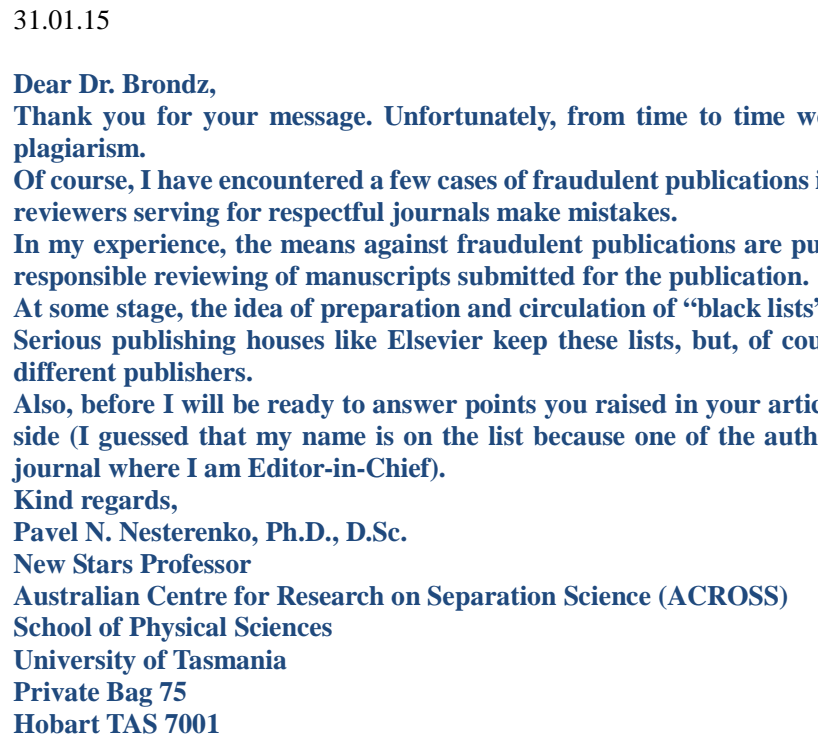

Figure 2. The answer from Editor in Chief: Pavel N. Nesterenko Current Chromatography.

\subsection{2 .15}

Pavel N. Nesterenko, Ph.D., D.Sc.

New Stars Professor

Australian Centre for Research on Separation Science (ACROSS)

School of Physical Sciences, University of Tasmania, Private Bag 75

Hobart TAS 7001 pavel.nesterenko@utas.edu.au

AUSTRALIA

Dear Professor Pavel N. Nesterenko,

Good day.

Thank you for your reply. The arrival of your email was expected. I have no intention to put you on a "black list"; however, I expect the retraction of the paper and removal from his position of Associate Editor H.Y. Aboul-Enein (National Research Centre, Cairo, Egypt), the corresponding author of the fraudulent paper. I am proceeding with these actions against members of the editorial board or even EICs involved in plagiarism or fraud. I have started my activity in this direction after a "personal appeal by David J.W. Lane the Editor-inChief of Research and Reports in Biodiversity Studies to support and promote the international author standards as developed by COPE for authors and editors-in-chief posted to me April 3rd 2012 (International standards for editors and authors http://www.dovepress.com/rrbscope.t9699812)." As a member of ACS I also have a duty to clean up the field of scientific publications from plagiarism and fraud.

Please feel free to contact me if you have any questions!

Kind regards,

Dr. Ilia Brondz, Editor in Chief of Scientific Research Publishing Inc. USA

http://www.scirp.org/journal/DetailedInforOfEditorialBoard.aspx?personID=8618

Figure 3. Answer to Editor in Chief: Mr. Nesterenko Current Chromatography. 
13.03 .15

Pavel N. Nesterenko, Ph.D., D.Sc.

New Stars Professor

Australian Centre for Research on Separation Science (ACROSS)

School of Physical Sciences

University of Tasmania

Private Bag 75

Hobart TAS 7001

AUSTRALIA

pavel.nesterenko@utas.edu.au

Dear Pavel,

Good day.

I hope this email finds you well.

I consider that you as an Editor in Chief of journal Current Chromatography have a moral duty to clean up the editorial board from cheaters and falsifiers. I consider that you as an Editor in Chief have a moral duty to obtain an explanation for the bold falsification presented by the Associate Editor (H.Y. Aboul-Enein, National Research Centre, Cairo, Egypt) in the papers: Elbashir, A.A., Saad, B., Ali, A.S.M., Saleha, M.I., and Aboul-Enein, H.Y. (2009) "Determination of Quinocide as Impurity in Primaquine Tablets by Capillary Zone Electrophoresis,” Biomedical Chromatography, 23, 464-471. http://dx.doi.org/10.1002/bmc.1137 and Elbashir, A.A., Saad, B., Ali, A.S.M., Saleha, M.I., and Aboul-Enein, H.Y. (2008), "Development of a Capillary Electrophoresis Method for the Enantioselective Estimation of Primaquine in Pharmaceutical Formulations,” Journal of AOAC International, 91, 536-541. I consider that you as an Editor in Chief have a moral duty to inform me about the results.

I would like to inform you that I am preparing the next paper in the series: "Analytical Methods in Quality Control of Scientific Publications" and the team described in my recent paper will also be named in the new paper in connection with a new falsification. I would not like your name to be in the same company in connection with hosting H.Y. Aboul-Enein as Associate Editor in the journal Current Chromatography. I hope that you will do your best to clean up the journal from fraud and clear your name from suspicion of concealing plagiarists, falsifiers and rogues.

Please feel free to contact me if you have any questions!

Sincerely yours,

Dr. Ilia Brondz,

Director of Norwegian Drug Control and Drug Discovery Institute (NDCDDI) AS,

Norway

Editor in Chief of Scientific Research Publishing Inc.USA

http://www.scirp.org/journal/DetailedInforOfEditorialBoard.aspx?personID=8618

Figure 4. This letter to Mr. Nesterenko has not yet received a reply.

\section{What Was Wrong?}

What was wrong in paper [28] and several other papers that used spectrophotometric techniques? Before presentation [3] and the following series of papers [7] [8] [17]-[26], the publication of papers such as [30]-[35] were partly excusable because of the absence of information about contamination with quinocide. After presentation of [3] [7] [8] [17]-[26], it is not acceptable for serious scientists to publish such data as [28]. The isomers undergo the same derivatization and give the similar UV spectra. It is not possible by these reactions and UV spectroscopic measurements to differentiate the constitutional isomers or to quantify them correctly. Chromatographic or capillary electrophoretic methods must be used [3] [7] [8] [17]-[26]. In publication [28], the authors were well aware of the presence of isomers in their analytical procedure, because they previously published papers [2] [27]. Publication [28] should be considered as a direct service to the pharmaceutical industry to conceal the fact of the presence of contaminants. Despite the knowledge of the reviewers, editors and editors in chief that this team continually publishes fraudulent papers, the papers were published with the help of their patrons from the pharmaceutical industry.

\section{Appeal}

I cannot dismiss the Editor in Chief of Journal of Pharmaceutical and Biomedical Analysis in Elsevier, Mr. Bezhan Chankvetadze jpba_bezhan@yahoo.com, as even he is involved in concealing fraudulent papers such as 
[1]. I cannot dismiss the Editor in Chief of Asian Journal of Chemistry, Mr. Agarwal for his involvement in disseminating unpublished manuscripts submitted to Asian Journal of Chemistry to Indian "scientists" to boost their image, but I can apply to you, Mr. Nesterenko, to free by your own "free" will the position of member of editorial board in Journal of Analytical Sciences, Methods and Instrumentation of Scientific Research Publishing Inc. USA to avoid to be fired with shame from this position. You are Editor in Chief of Current Chromatography and you are hosting cheater and falsifier Associate Editor Mr. H.Y. Aboul-Enein in Current Chromatography. It is not acceptable to host in Current Chromatography a plagiarist, cheater and falsifier as an Associate Editor. I cannot allow the presence of the editors with such background as you Mr. Nesterenko in our journals.

\section{Discussion}

The derivatization reactions and subsequent UV spectrometric quantitative and qualitative analysis require careful checks for the presence of interfering factors and substances. In particular, this is necessary for pharmaceutical products and methods under development. This was not done in paper [28], even though the authors well knew that primaquine contains its isomer quinocide. There is no doubt about that this publication falsifies facts so as to hide the presence of a toxic substance mixed with the antimalarial drug primaquine. Analytical chromatography must be used in these cases.

\section{Conclusion}

No publisher who wishes to be numbered among the recognized, honest, publishers with professional integrity can allow the accommodation of plagiarists and corrupt editors. The only way to avoid double publications, fraudulent presentations and falsifications in science, arts, social life and politics is to keep swindlers out of the important field of public information. We are in journal Voice of the Publisher open to receive readers' contributions as papers, letters to the editor and other presentations to discuss this important subject. Please submit yours manuscripts to the journal Voice of the Publisher http://www.scirp.org/journal/vp/ or direct to me, Dr. Ilia Brondz, Editor in Chief of Scientific Research Publishing Inc. USA Website:

http://www.scirp.org/journal/DetailedInforOfEditorialBoard.aspx?personID=8618 by e-mail:

ilia.brondz@gmail.com.

\section{References}

[1] Dongre, V.G., Karmuse, P.P., Nimbalkar, M.M., Singh, D. and Kumar, A. (2005) Applications of GC-EI-MS for the Identification and Investigation of Positional Isomer in Primaquine, an Antimalarial Drug. Journal of Pharmaceutical and Biomedical Analysis, 39, 111-116. http://dx.doi.org/10.1016/j.jpba.2005.03.019

[2] Elbashir, A.A., Saad, B., Ali, A.S.M., Saleha, M.I. and Aboul-Enein, H.Y. (2009) Determination of Quinocide as Impurity in Primaquine Tablets by Capillary Zone Electrophoresis. Biomedical Chromatography, 23, 464-471. http://dx.doi.org/10.1002/bmc.1137

[3] Brondz, I., Mantzeilas, D., Klein, U., Lebedeva, M.N., Mikhailitsyn, F.S., Souleimanov, G.D. and Ekeberg, D. (2003) The Main Contaminant of the Anti-Malaria Drug Primaquine Is Its Positional Isomer. 3rd International Symposium on Separation in BioSciences SBS 2003 A 100 Years of Chromatography, Moscow, 13-18 May 2003, Abstract P-57, 165.

[4] Schmidt, L.H., Alexander, S., Allen, L. and Rasco, J. (1977) Comparison of the Curative Antimalarial Activities and Toxicities of Primaquine and Its $d$ - and l-Isomers. Antimicrobial Agents Chemotherapy, 12, 51-60. http://dx.doi.org/10.1128/AAC.12.1.51

[5] Baker, J.K., Yarber, R.H., Nanayakkare, N.P.D., McChesney, J.D., Homo, F. and Landau, I. (1990) Effects of Aliphatic Side-Chain Substituents on the Antimalarial Activity and on the Metabolism of Primaquine Studied Using Mitochondria and Microsome Preparations. Pharmacological Research, 7, 91-95. http://dx.doi.org/10.1023/A:1015899928897

[6] Saunders, D., Vanachayangkul, P., Imerbsin, R., Khemawoot, P., Siripokasupkul, R., Tekwani, B.L., Sampath, A., Nanayakkara, N.P.D., Ohrt, C., Lanteri, C., Gettyacamin, M., Teja-Isavadharm, P. and Walker, L. (2014) Pharmacokinetics and Pharmacodynamics of (+)-Primaquine and (-)-Primaquine Enantiomers in Rhesus Macaques (Macacamulatta). Antimicrobial Agents Chemotherapy, 58, 7283-7291. http://dx.doi.org/10.1128/AAC.02576-13

[7] Brondz, I., Mantzilas, D., Klein, U., Ekeberg, D., Hvattum, E., Lebedeva, M.N., Mikhailitsyn, F.S., Souleimanov, G.D. and Røe, J. (2004) Nature of the Main Contaminant in the Anti-Malaria Drug Primaquine Di-Phosphate: A Qualitative Isomer Analysis. Chromatography B: Biomedical Sciences and Applications, 800, 211-223. http://dx.doi.org/10.1016/j.jchromb.2003.09.042 
[8] Brondz, I. (2011) Historical Overview of Chromatography and Related Techniques in Analysis of Antimalarial Drug Primaquine. Nova Science Publishers, Inc., New York.

[9] (1988) British Pharmacopoeia. Vol. I, HMSO, London, 462.

[10] (1988) British Pharmacopoeia. London, HMSO. (Addendum, 1990, 1252)

[11] Brondz, I. (2014) Review: Can Toxic Substances Initiate Psychotic Behavior? Part I. Anti-Malarial Drugs. Open Journal of Preventive Medicine, 4, 561-572. http://dx.doi.org/10.4236/ojpm.2014.47066

[12] (1993) British Pharmacopoeia, Vol. I, London, HMSO, 2015. (Addendum, 1997)

[13] (1997) European Pharmacopoeia. 3rd Edition, Council of Europe, Strasbourg, 1385.

[14] (2000) British Pharmacopoeia, Vol. I, London, HMSO, 1285.

[15] (2001) European Pharmacopoeia. 3rd Edition, Council of Europe, Strasbourg, 1323. (Supplement)

[16] (2008) The United States Pharmacopeia, 31 Revision and The National Formulary. 26th Edition, Vol. 3, The United States Pharmacopeia Convention, Rockville.

[17] Brondz, I., Klein, U., Ekeberg, D., Mantzilas, D., Hvattum, E., Schultz, H. and Mikhailitsyn, F.S. (2004) Nature of the Main Contaminant in the Anti-Malaria Drug Primaquine Di-Phosphate: GC-MS Analysis. International Symposium Analytical Forum 2004, Warsaw, 4-8 July 2004, 119, 154.

[18] Brondz, I., Klein, U., Ekeberg, D., Mantzilas, D., Hvattum, E., Schultz, H. and Mikhailitsyn, F.S. (2005) Nature of the Main Contaminant in the Anti-Malaria Drug Primaquine Di-Phosphate: GC-MS Analysis. Asian Journal of Chemistry, 17, 1678-1688.

[19] Brondz, I. and Klein, U. (2005) Separation of the Positional Isomer Quinocide from the Anti-Malarial Drug Primaquine Using a Discovery ${ }^{\circledR}$ HS F5 HPLC Column. The Reporter, 23, 1.

[20] Brondz, I., Ekeberg, D., Karaliova, L., Jennings, I., Hustad, J.A. and Svendsen, R. (2005) Separation of the Positional Isomer Quinocide from the Anti-Malaria Drug Primaquine Using a Discovery ${ }^{\circledR}$ HS-F5 HPLC Column. Trends in Chromatography, 1, 78-81.

[21] Brondz, I., Klein, U., Karaliova, L., Vlachos, V., Oakley, P., Leideborg, R. and Mikhalitsyn, F. (2005) Nature of the Main Contaminant in the Drug Primaquine Di-Phosphate: Comparison of HPLC and SFC Methods. 29th International Symposium on High Performance Liquid Phase Separations and Related Techniques, Stockholm, 26-30 June 2005, 430.

[22] Brondz,I. Ekeberg,D. Annino, A. R. Palcic,T. (2007), SFC-MS Analyses of Anti-Malaria Drug Primaquine Diphosphate. Comparison of Techniques and Instrumentation. 12th Norwegian MS-Winter Meeting, Hafjell, 21-24 January 2007, 42.

[23] Brondz, I., Ekeberg, D., Bell, D.S., Hustad, J.A., Svendsen, R., Vlachos, V., Oakley, P., Langley, G.J., Mohini, T., Amaury, C.-G. and Mikhalitsyn, F. (2007) Nature of the Main Contaminant in the Drug Primaquine Diphosphate: SFC and SFC-MS Methods of Analysis. Journal of Pharmaceutical and Biomedical Analysis, 43, 937-944. ttp://dx.doi.org/10.1016/j.jpba.2006.09.017

[24] Brondz, I. (2009) SFC-MS Analysis of Contaminants in Primaquine Diphosphate Tablets and Spectral UV and NMR Characterizing of Primaquine and Quinocide. 5th Conference of Nordic Separation Science Society, Tallinn, 26-29 August 2009, Abstract PP07.

[25] Brondz, I. Fialkov, A.B. and Amirav, A. (2009) Analysis of Quinocide in Unprocessed Primaquine Diphosphate and Primaquine Diphosphate Tablets Using Gas Chromatography-Mass Spectrometry with Supersonic Molecular Beams. $J$. Chromatography A, 1216, 824-829. http://dx.doi.org/10.1016/j.chroma.2008.11.043

[26] Brondz, I. (2011) In Vitro Techniques in Analysis of Antimalarial Drug Primaquine (Historical Overview of Chromatography and Related Techniques in Analysis of Antimalarial Drug Primaquine). 7th Annual BioMalPar Conference on the Biology and Pathology of the Malaria Parasite, Heidelberg, 16-18 May 2011, 80.

[27] ElBashir, A.A., Saad, B., Ali, A.S.M., Saleha, M.I. and Aboul-Enein, H.Y. (2009) Enantioselective Analysis of Primaquine and Its Impurity Quinocide by Capillary Electrophoresis. Biomedical Chromatography, 23, 295-301. http://dx.doi.org/10.1002/bmc.1113

[28] Altigani, A.M.N. and Elbashir, A.A. (2014) Spectrophotometric Method for Determination of Primaquine in Pharmaceutical Formulations via Derivatization with 1,2-Naphthoquinone-4-Sulfonate. Austin Journal of Analytical and Pharmaceutical Chemistry, 1, 1019.

[29] Brondz, I. (2014) Analytical Methods in Quality Control of Scientific Publications Part IV: Fraud Ordered by the Pharmaceutical Industry. International Journal of Analytical Mass Spectrometry and Chromatography, 2, 103-112. http://dx.doi.org/10.4236/ijamsc.2014.24009

[30] Luk’yanchikova, G.I., Bernshtein, V.N. and Prokoshev, A.A. (1970) Quantitative Determination of Quinocide and Quinosol. Farmatsiya, 19, 84. 
[31] Abdel, S.M. Issa, A.S. and Lymona, H. (1986) Utility of the Charge-Transfer Complex Formation for the Spectrophotometric Determination of Some Antimalarials. Journal de Pharmacie de Belgique, 41, 314-318.

[32] Sasty, B.S., Rao, E.V., Tumuru, M.K. and Sastry, C.S.P. (1986) A New Spectrophotometric Method for the Estimation of Primaquine Using MBTH. Indian Journal of Pharmaceutical Sciences, 48, 190-192.

[33] Rao, R.G., Murty, S.S.N. and Raju, I.R.K. (1988) Spectrophotometric Determination of Primaquine Phosphate with Ninhydrin. Indian Drugs, 26, 86-88.

[34] Sasty, B.S., Rao, E.V., Tumuru, M.K. and Sastry, C.S.P. (1989) Estimation of Primaquine in Its Formulations. Indian Drugs, 27, 260-261.

[35] Amin, A.S. and Issa, Y.M. (2000) Spectrophotometric Microdetermination of Some Pharmaceutically Important Aminoquinoline Antimalarials, as Ion-Pair Complexes. Microchimica Acta, 134, 133-138. http://dx.doi.org/10.1007/s006040070028 